\title{
PROCEEDINGS FROM
}

\section{Semantics \\ and}

Linguistic

Theory

IV

HELD AT THE

UNIVERSITY OF ROCHESTER

MAY 6-8, 1994 



\title{
PROCEEDINGS FROM
}

\section{Semantics and \\ Linguistic Theory IV}

\author{
Edited by \\ Mandy Harvey and Lynn Santelmann
}

Cornell University

Department of Modern Languages and Linguistics

Ithaca 1994 


\section{Contents}

Nicholas Asher and Pierre Sablayrolles

A Compositional Spatio-temporal Semantics for French

Motion Verbs and Spatial PPs

Emmon Bach

The Meanings of Words

David Beaver

When Variables Don't Vary Enough

Mary Dalrymple, Makoto Kanazawa, Sam Mchombo and Stanley Peters

What do Reciprocals Mean?

Paul Dekker

Predicate Logic with Anaphora

Viviane Déprez

Questions with Floated Quantifiers

David Dowty

The Role of Negative Polarity and Concord Marking

in Natural Language Reasoning

Jack Hoeksema

A Semantic Argument for Complex Predicates

Pauline Jacobson

Binding Connectivity in Copular Sentences

Emiel Krahmer and Reinhard Muskens

Umbrellas and Bathrooms

Manfred Krifka

The Semantics and Pragmatics of Weak and

Strong Polarity Items in Assertions

William A. Ladusaw

Thetic and Categorical, Stage and Individual, Weak and Strong

Sally McConnell-Ginet

On the Non-Optionality of Certain Modifiers

Toshiyuki Ogihara

Adverbs of Quantification and Sequence-of-Tense Phenomena 
Matthias Paul

Young Mozart and the Joking Woody Allen

Proper Names, Individuals and Parts

Massimo Poesio

Weak Definites

282 


\title{
Acknowledgments
}

This proceedings contains papers presented at the fourth conference on Semantics and Linguistic Theory, May 6-8, 1994, at the University of Rochester. 19 papers were presented at the conference; 14 of those are in this volume. Also included are the alternate papers for the conference. Thanks to the authors of the papers which appear here for their cooperation in submitting camera-ready copy. Unfortunately, the papers presented by the following authors were not available for publication in this volume: Robin Cooper, Veneeta Dayal, Kai von Fintel, Jo-want Lin and Craige Roberts.

The conference was organized by Chris Barker, Greg Carlson, Claudia Ho, Graham Katz, Peter Lasersohn and Beverly Spe jewski. Many thanks to them, and to the University of Rochester Linguistics Department, the Center for the Sciences of Language, the Cognitive Science Program, and the College of Arts and Science for making the conference possible. Thanks also to Roberta Colon for administrative work, to our abstract reviewers, and to everyone who helped with registration, cleaning up, and various other chores.

Finally, thanks to the Department of Modern Languages and Linguistics at Cornell University and especially to Michael Bernstein for making this publication possible.

\author{
Mandy Harvey \\ Lynn Santelmann \\ Editors
}


